normal infants who were fed from the age of 2 months until 12 months old on either fresh cow's milk or a prepared formula which was introduced into the diet. At the end of the study the infants fed fresh cow's milk had a marginally lower haemoglobin level and mean cell volume; their serum iron concentration was lower at 6 months of age but not different from the normal group at 12 months. Occult blood tests were positive in most of the infants in both groups. Milk antibodies were found in four of the infants fed fresh milk and in one fed the formula when tested at 12 months of age.

This study did not show a striking difference in the iron status of the normal babies fed fresh milk compared with those receiving formula, and the relevance of these studies to those carried out on infants with established iron-deficiency anaemia is conjectural. The possibility of individual susceptiblity to fresh cow's milk in those with iron-deficiency anaemia cannot be excluded. It remains to be seen how common this condition is, and the exact way in which the enteropathy and the iron-deficiency develop and their interrelationship require further elucidation.

1 Wilson, J. F., Heiner, D. C., and Lahey, M. E., fournal of the American Medical Association, 1964, 189, 568.

2 Hoag, M. S., Wallerstein, R. O., and Pollycove, M., Pediatrics, 1961, 27, 199 .

3 Schubert, W. K., and Lahey, M. E., Pediatrics, 1959, 24, 710.

4 Naiman, J. L., Oski, F. A., Diamond, L. K., Vawter, G. F., and Schwachman, H., Pediatrics, 1964, 33, 83.

5 Visakorpi, J. K., and Kuitunen, P., Annales Paediatriae Fenniae, 1966, 12

- Guha, D. K., Walia, B. N. S., Tandon, B. N., Deo, M. G., and Ghai, O. P., Archives of Disease in Childhood, $1968,43,239$.

7 Woodruff, C. W., and Clark, J. L., American fournal of Diseases of Children, $1972,124,18$

${ }^{8}$ Katz, J., Spiro, H. M., and Herskovic, T., New England fournal of Medicine, 1968, 278, 1191 .

- Woodruff, C. W., Wright, S. W., and Wright, R. P., American fournal of Diseases in Children, 1972, 124, 26.

\section{"Steal" Syndromes and Hypertension}

When an artery becomes obstructed blood may be diverted into its distal segment, where the pressure is lower, via collaterals from a normally perfused arterial territory nearby. Hypoxia-induced vasodilatation may cause further diversion, and if this becomes excessive it may actually lead on to ischaemic symptoms in the donor territory. This mechanism has been called arterial "steal." Blood is stolen from the healthy territory, and the result is to give a false localization of the site of the arterial disease.

The first steal syndrome to be described resulted from reversed flow down the vertebral artery into the subclavian artery beyond a stenosis in its first part. ${ }^{1}$ Symptoms of brainstem ischaemia precipitated by arm exercise were reported. Subclavian steal does not always follow occlusion near the origin of the subclavian artery. It is rare after subclavian-pulmonary artery anastomosis for the palliation of the tetralogy of Fallot, and the anatomy of the circle of Willis in individual patients probably determines the outcome.

The concept of the steal syndrome proved to be attractive, and aorto-iliac, ${ }^{2}$ mesenteric, ${ }^{34}$ spinal,, $5^{5}$ and coronary 6 steals have since been described.

The concept of coronary steal is interesting but difficult to prove. D. B. Effler and associates at the Cleveland
Clinic, Ohio, suggested the term "coronary steal" for the situation which arises in the anomalous origin of the left coronary artery from the pulmonary artery. ${ }^{7}$ In this condition blood flows from the normally arising right coronary artery via intercoronary anastomoses into the lower-pressure left coronary artery and thus retrograde into the pulmonary artery. Blood is "stolen" from the territory of the normal coronary artery. Ligation of the anomalous coronary artery at its origin from the pulmonary artery can alleviate the symptoms of myocardial ischaemia. More recently it has been postulated that a similar diversion of flow may occur in acquired occlusive coronary artery disease. ${ }^{8}$ We are accustomed at coronary angiography to seeing retrograde filling of the distal segment of a coronary artery beyond an obstruction. Thus contrast injected into the left coronary artery may fill the distal part of an obstructed right coronary artery. Certain coronary vasodilator dugs have been known to precipitate angina. By causing vasodilatation in the healthy parts of the coronary tree it is possible that they may reduce collateral flow and steal blood away from an ischaemic territory.

Now R. J. Alfidi and colleagues, of the Cleveland Clinic, have added three further cases of renal-splanchnic steal to the original example reported in 1967.910 In Alfidi and colleagues' patients renal ischaemia, with consequent hypertension, resulted from diversion of blood away from the right kidney into branches of the coeliac axis distal to obstruction of its main stem. The four patients, all women, had large collateral arteries running upwards from the right renal artery into a radical of the coeliac axis. All four patients had presented with high blood pressure. Two of them had a bruit in the abdomen. Renal artery stenosis was suspected but none found. Instead they all showed arterial flow away from the right kidney to enter an enlarged inferior adrenal artery and thence via a superior renal artery to a branch of the coeliac artery. The diagnosis of hypertension due to this mechanism depends on failure to find stenosis of a renal artery in a patient in whom this has been suspected, recognition of the enlarged vessels leaving the kidney, and angiographic demonstration of a stenosis of the coeliac axis.

The authors warn against surgical ligation of the steal vessels, because interruption of the collateral supply to the splanchnic bed could precipitate mesenteric angina or even gangrene of the small intestine. This actually occurred after spontaneous thrombosis of the steal vessel in one of their patients. They recommend that surgical efforts should be directed towards re-establishment of a normal splanchnic blood supply, as this would eliminate the renal steal and correct ischaemia in both the donor and the recipient territory. As in other types of renal hypertension due to renal ischaemia, the high blood pressure may persist even after removal of its cause.

1 Reivich, M., Holling, H. E., Roberts, B., and Toole, J. F., New England fournal of Medicine, 1961, 265, 878

Kountz, S. L., Laub, D. R., and Connolly, J. E., Archives of Surgery, 1966, 92, 490.

Reuter, S. R., and Olin, T., Radiology, 1965, 85, 617.

Bucheler, E., Düx, A., and Rohr. H., Fortschritte auf dem Gebiete der Röntgenstrahlen und der Nuklearmedizin, 1967, 106, 313.

5 Doppman, J. L., Di Chiro, G., and Ommaya, A. K.. Selective Arteriography of the Spinal Cord, p. 67. St. Louis, Warren H. Green, 1969.

Baker, L. D., Snow, J. A., Pomposiello, J. C., Sharma, G.V.R.K., and Messer, J. V., Clinical Resea"ch, 1969, 17, 228.

7 Effler, D. B., Sheldon. W. C., Turner, J. J., and Groves, L. K., Surgery, 1967, 61. 41

8 Fam, W. M., and McGregor, M., Circulation Research, 1964, 15. 355 9 Alfidi, R. J., Filson. E. J., and Frohlich, E. D., Cleveland Clinical Ouarterly, $1967,34,43$.

10 Alfidi, R. J., et al., Radiology, 1972, 102, 545. 